ISSN: 1641-4713; e-ISSN: 2081-1160

DOI: https://doi.org/10.36551/2081-1160.2021.28.295-310

\title{
Os riscos do silenciamento: Diferentes perspectivas nos processos de tomada de decisão na elaboração de políticas públicas de memória no contexto da redemocratização brasileira $^{1}$
}

The risks of silencing: different perspectives on the decision-making processes in the establishment of public policies of memory in the context of Brazilian redemocratization

Fernanda R. Abreu Silva

Pontifícia Universidade Católica do Rio de Janeiro (PUC-Rio), Brasil ORCID iD: https://orcid.org/0000-0002-1017-1271

E-mail: fernandaabreu2@gmail.com

Recepción: 4.05.2021

Aprobación: 19.12.2021

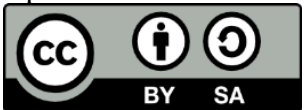

Resumo: Trata-se de uma análise dos processos de tomada de decisão na elaboração de políticas públicas de memória executadas no Brasil entre as décadas 1990 e 2010. Considerando a Lei de Anistia como uma importante chave analítica para o processo de redemocratização do país, tendo orientado as ações de memória, verdade e justiça ao longo desse período, desenvolvemos o termo política pública de silenciamento visando compreender as negociações em torno da elaboração dessas medidas sob a convergência de três diferentes perspectivas sobre como lidar com o passado autoritário que se mantiveram em constante disputa nesse cenário.

Palavras-chave: justiça de transição, lei de anistia, redemocratização, políticas públicas, memória

${ }^{1} \mathrm{O}$ presente trabalho foi realizado com apoio da Coordenação de Aperfeiçoamento de Pessoal de Nível Superior - Brasil (CAPES) - Código de Financiamento 001. 


\begin{abstract}
It is an analysis of the decision-making processes in the establishment of public policies of memory achieved in Brazil between the 1990s and 2010, still in progress. Considering the Amnesty Law as an important analytical key for the re-democratization process, guiding the actions of memory, truth, and justice throughout this period, we developed the concept of public policy of silencing in order to understand the negotiations around the formulation of these measures under the convergence of three different perspectives on how to deal with the authoritarian past in a steady contest in this scenario.
\end{abstract}

Keywords: transitional justice, amnesty law, redemocratization, public policies, memory.

\title{
INTRODUÇÃO
}

A transição política entre o regime ditatorial e o democrático caracterizou-se pelo controle e pela negociação entre os atores políticos, de modo que os militares permaneceram como veto players ao longo da redemocratização. A hipótese defendida é que as políticas e medidas de memória, verdade e justiça foram limitadas e esta limitação foi provocada pelo que chamamos de política pública de silenciamento, implementada deliberada e intencionalmente por atores remanescentes da elite política do período autoritário. Como fontes, são utilizadas entrevistas de História Oral com figuras públicas relevantes no desenvolvimento de políticas públicas de memória e verdade, sejam representantes do Estado, como ex-ministros da Justiça e secretários de Direitos Humanos, sejam ativistas de movimentos sociais de atingidos políticos. Essas entrevistas foram elaboradas pelos projetos "Marcas da Memória: história oral da anistia no Brasil" (2010-2013), realizado na Universidade Federal do Rio de Janeiro, "Arqueologia da Reconciliação: formulação, aplicação e recepção de políticas públicas relativas à violação de direitos humanos durante a ditadura militar" (2014-2016), elaborado pelo Centro de Pesquisa e Documentação em História Contemporânea do Brasil, da Fundação Getúlio Vargas e, por fim, o projeto "Ciclo Memória, Movimentos Sociais e Direitos Humanos" (2019), realizado pelo Núcleo de Memória e Direitos Humanos da UFRJ. Este artigo se propõe a apresentar brevemente alguns resultados da nossa pesquisa de doutorado em Direito, com ênfase em Direitos Humanos, recentemente defendida na Pontifícia Universidade Católica do Rio de Janeiro.

\section{COMO LIDAR COM A HERANÇA AUTORITÁRIA? EMBATES DE TRÊS DIFERENTES PERSPECTIVAS PARA O TRATO COM O PASSADO}

Se comparado com os demais países latino-americanos, o processo de acerto de contas brasileiro com seu passado autoritário sofreu profundas limitações, podendo ser lido como insuficiente a partir tanto do ponto de vista dos 
atingidos políticos, quanto do Direito Internacional dos Direitos Humanos. Embora tenha havido avanços nas políticas de memória e verdade, sobretudo entre 2007 e 2014, o Brasil experienciou uma política pública de silenciamento gestada durante a abertura política e conduzida pelos atores políticos herdeiros da ditadura ao longo da redemocratização, sobretudo através do poder de veto informal das Forças Armadas.

Apesar de suas particularidades, os países do Cone Sul compartilharam um mesmo contexto de regimes autoritários em meio à Guerra Fria, com influências estrangeiras e repressão a um inimigo comum: a suposta expansão do comunismo. Entre suas semelhanças, podemos destacar a ação sistemática de repressão, o terror de Estado (Padrós, 2004), a cultura do medo (Bauer, 2011) e a concomitância do início das redemocratizações na década de 1980. Entretanto, a correspondência brasileira com os demais não é observável no período pós-autoritário; a instalação de comissões da verdade é um bom exemplo para observar a diferença de cada país no tratamento do passado, na maioria deles tendo ocorrido logo no início da redemocratização, enquanto no Brasil foram décadas de espera. ${ }^{2}$

Nesses trinta anos, foram publicados inúmeros estudos que visam compreender essa diferença entre os países latino-americanos, centenas de ótimas análises comparativas tanto entre as ditaduras quanto entre as democracias (ver Bauer, 2011; Mezarobba, 2008), porém o foco deste trabalho não é propriamente uma análise comparativa. Recorremos à breve apresentação dos processos de justiça de transição dos países do Cone Sul visando pôr o processo brasileiro em perspectiva, com o propósito de fundamentar nas próximas páginas a noção de política pública de silenciamento, aqui desenvolvido. $\mathrm{O}$ termo surge para caracterizar a limitação no processo de divulgação e acesso à memória da ditadura brasileira durante o período de redemocratização, tendo em mente que, embora tenha havido uma movimentação do Estado em prol de políticas e medidas de memória entre 2007 e 2014, estas permaneceram circunscritas aos grupos diretamente afetados, como familiares de mortos e desaparecidos, ex-perseguidos políticos e movimentos de defesa de direitos humanos. Assim, afastando-se da sociedade como um todo, de modo que esta não se percebe lesionada pelas arbitrariedades do autoritarismo, tampouco os seus efeitos.

\footnotetext{
${ }^{2} \mathrm{Na}$ Argentina, em 1983, foi criada a Comissão Nacional sobre o Desaparecimento de Pessoas. Em seguida, o Uruguai criou a Comissão Investigadora sobre a Situação de Pessoas Desaparecidas e Fatos que a Motivaram em 1985 e a Comissão para a Paz em 2000. No Chile, a Comissão Nacional da Verdade e Reconciliação foi inaugurada em 1990, seguida da Comissão Nacional de Reparação e Reconciliação em 1992 e da Comissão Nacional sobre Prisão Política e Tortura em 2003.
} 
Optamos por "silenciamento", pois não se trata de um apagamento completo em que as vozes dissonantes não tenham espaço algum, mas de uma ação deliberada do Estado de permitir que essas vozes ecoem controladamente. Dessa forma, a "memória dos vencidos" permanece ativa, porém circunscrita aos espaços em que não possam causar maiores efeitos e não agrega a sociedade em sua completude. Discretos avanços são permitidos conforme a força da pressão exercida pelos grupos diretamente interessados e, sobretudo, conforme a condição política pela qual o país esteja enfrentando. Portanto, a insuficiência provocada pela limitação às políticas públicas de memória, verdade e justiça no Brasil pode ser considerada per si como uma política pública em que atores políticos intencionalmente trabalham para impedir um maior avanço da temática no plano público.

Através da análise das fontes, foi possível perceber três diferentes perspectivas de como lidar com o passado autoritário no processo de acerto de contas brasileiro que estiveram em constante embate durante todo o período pós-ditatorial. Por meio da Lei de Anistia de 1979, a primeira perspectiva (dos conservadores) - de manutenção do status quo, de busca pela "página virada, capítulo da história encerrado" - conseguiu implementar a política pública de silenciamento na qual os atores se articularam de modo a manter o debate sobre o passado apenas como uma questão privada, individual, e não coletiva. A segunda perspectiva (dos atingidos) encara o tratamento do passado a partir de um posicionamento mais crítico - e muitas vezes desconfiado -, tanto levanta demandas mais contundentes (provocando uma intensa pressão no Estado), quanto suspeita de qualquer ação do Estado. Já a terceira perspectiva (dos negociadores) é a que condensa a estratégia de acomodação da cultura política brasileira (Motta, 2018), isto é, busca alternativas para o avanço das pautas de justiça de transição esbarrando nos limites impostos pelos atores partidários da primeira perspectiva. Para tal, os representantes da terceira perspectiva se inseriram e utilizaram das estruturas do Estado para dar prosseguimento às pautas - especialmente de memória e verdade, sobrepondo-as à justiça em razão das possibilidades presentes no manejo político. Dessa atuação, dois resultados diametralmente opostos foram observados: por um lado, todo avanço na construção de políticas de memória e verdade no Brasil, entre as décadas de 1990 e 2010, ocorreu por meio desses atores mais abertos à negociação política. Por outro, ainda que tenham agido de boa-fé, em algum grau colaboraram não-intencionalmente para compor essa política pública de silenciamento na medida em que, na busca de não mostrar um suposto "revanchismo", evitaram o avanço profundo dessas mesmas pautas e, sobretudo, da justiça. 
De certo o processo não foi inteiramente controlado pelos atores da primeira perspectiva, pois, se assim fosse, teriam suprimido as possibilidades de prosseguimento dessas demandas. No entanto, foram bem-sucedidos em operar o poder de veto praticado pelos militares a cada vez que, a Lei de Anistia era ameaçada - ainda que sutilmente -, como aponta D'Araújo (2012), e se novamente voltarmos à comparação com os países latino-americanos, embora o Brasil não tenha sido o único a adotar uma lei de autoanistia, é o único em que o veto dos militares garantiu que nenhum agente público envolvido com violações de direitos humanos fosse sequer julgado pelos crimes cometidos.

\section{O PROTAGONISMO DA LEI DE ANISTIA E A "PÁGINA VIRADA"}

A Lei de Anistia de 1979 ocupa um papel de centralidade no processo político brasileiro, tendo em vista que é constantemente mobilizada pela perspectiva conservadora sob a leitura de que representa um instrumento de reconciliação entre os supostos "dois lados", ou seja, entre a força do Estado e a resistência dos militantes. Essa lógica deu origem à narrativa do consenso que equipara os movimentos de resistência à ação repressiva do Estado, em que apenas uma "minoria" teria cometido "excessos" de ambos os lados. Apesar de semelhante no aspecto da equivalência de forças, a narrativa da memória consensual (E. Teles, 2015) se diferente da chamada "teoria dos dois demônios" à medida que esta foi forjada sob uma leitura de condenação da violência dos grupos resistentes, atribuindo a isso a escalada repressiva do Estado como uma resposta ou reação às ações dos militantes (Quinalha, 2013). Por sua vez, a memória do consenso, apesar de igualar as forças de violência da mesma forma, não atribui causalidade entre as ações de resistência e a violenta repressão estatal. Ambas, no entanto, colocam a sociedade em posição passiva ante ao conflito, relegando os seus efeitos apenas a esses atores sociais.

Essa narrativa começou a ser construída ainda no debate legislativo, ancorado no discurso da promoção de uma "conciliação nacional" - discurso este que só foi possível devido ao controle empreendido pela ditadura sobre a transição política iniciada em 1974 sob o mote "distensão lenta, gradual e segura". Em meio à batalha de imagem (Fico, 2012), a posição do partido situacionista apresentou o teor da proposta antes mesmo da votação do projeto: a anistia seria um beneplácito, uma concessão do governo visando "pacificação" e "união dos brasileiros", porém reiterando que os condenados por terrorismo, sequestro, atentado pessoal e assalto não seriam incluídos. Os conflitos de narrativas também estive- 
ram presente entre os setores de oposição, as duas correntes (Rodeghero, 2012) mais mobilizadas eram a defendida pelo general cassado Pery Bevilacqua e deputados do Movimento Democrático Brasileiro (MDB), partido oficial de oposição consentida, e a predominante nos Comitês Brasileiros pela Anistia (CBA), grupos da sociedade civil organizada. Ambos defendiam uma anistia "ampla, geral e irrestrita", mas Bevilacqua acreditava que a anistia levaria a um consenso nacional e representaria "o perdão, o esquecimento, o eterno silêncio"(Rodeghero, 2012, p. 117); já os CBAs advogavam por uma anistia não recíproca, que conduzisse ao reconhecimento e à responsabilização pelas mortes e desaparecimentos políticos. Aqui podemos observar o conflito entre as duas primeiras perspectivas - dos conservadores e dos atingidos - na concepção da lei que ocuparia o centro do processo político brasileiro. E, em razão do controle desempenhado pela ditadura, o limite tolerável que o governo permitiu foi justamente a perspectiva do esquecimento, da página virada. Essa perspectiva permaneceu presente a partir de então, vigorando por uma década de silêncio absoluto. A esse silêncio, chamamos de fase amnésica (Gómez, 2018).

A narrativa da reconciliação por esquecimento, fruto da Lei de Anistia e da transição controlada, provocou uma barreira para o avanço do processo de acerto de contas com o passado e prejudicou o trabalho e a incorporação dessa memória traumática pela sociedade. Assim, a primeira perspectiva predominou completamente hegemônica, por longos 16 anos, após a publicação da lei e esse cenário começaria a se modificar apenas em 1995, quando foi criada a lei $\mathrm{n}^{\circ}$ 9.140. Nesse momento, os atores da segunda perspectiva (dos atingidos) conseguiram intensificar a pressão por eles exercida de modo a alcançar e obter resultados no novo governo que se instaurara. Trata-se do primeiro mandato do presidente Fernando Henrique Cardoso (1995-2002), ele próprio um ex-perseguido político que fora aposentado compulsoriamente e exilado durante a ditadura, e assim a emergência da terceira perspectiva (dos negociadores) é percebida com o presidente e os demais membros do seu governo, todavia de maneira tímida e incipiente.

Por meio da Lei de Mortos e Desaparecidos Políticos ( $\mathrm{n}^{\circ}$ 9.140/95), como ficou conhecida, o Estado reconheceu pela primeira vez a sua responsabilidade pela morte e desaparecimento dos militantes de oposição durante a ditadura. No entanto, ao manter-se nos limites da Lei de Anistia, não permitiu investigação das circunstâncias dessas violações, como também não outorgou responsabilidade individual ou mesmo institucional por esses crimes. Ademais, instituiu a Comissão Especial sobre Mortos e Desaparecidos Políticos 
(CEMDP) a fim de avaliar a inclusão de nomes na lista de atingidos publicada no anexo da lei, bem como pela concessão de indenização financeira aos familiares - restando o ônus da prova aos familiares e não ao Estado. Embora esta não tenha figurado como uma demanda principal do movimento civil, um dos autores da lei, o então chefe de gabinete do Ministério da Justiça, José Gregori, enxergou essa saída como um "remédio jurídico" (Gregori, 2015, p. 233) para esse tipo de situação.

O cargo de ministro da Justiça era ocupado por Nelson Jobim que encarregou Gregori de negociar com os familiares e demais setores civis para a construção do projeto de lei, enquanto o general Tamoio Pereira das Neves articularia com os setores militares. $\mathrm{O}$ argumento utilizado por Jobim junto a Neves e posteriormente aos militares era de que se "o problema dos mortos e desaparecidos" não fosse enfrentado, os "insepultos" circulariam pelo Palácio do Alvorada, portanto, "para superar o problema", era preciso "superar esse passado". E essa superação somente ocorreria se o assunto fosse encarado sem retaliação: "Ou seja, nós sabíamos que para construir uma solução de futuro, não se constrói retaliando o passado" (Jobim, 2014). Já Gregori explica que buscou preparar algo que fosse "um reconhecimento por parte do Estado de que houve o desaparecimento", o que não havia até então e seria traduzido na emissão de certidão de óbito. Assim, procurou driblar o argumento de que a lei seria um instrumento revanchista, levantado pelos militares, remetendo à Lei de Anistia no texto para que não houvesse "nenhum tipo de contaminação revanchista na lei" (Gregori, 2015).

Sob a mesma lógica, em seguida foi criada a Comissão de Anistia (lei $\left.n^{\circ} 10.559\right)$, em 2002, voltada exclusivamente para concessão de indenizações de caráter restitutivo, a fim de cumprir as determinações estabelecidas no art. $8^{\circ}$ da ADCT/Constituição Federal de 1988. O direito à reparação financeira foi estendido em relação à lei $n^{\circ} 9.140 / 95$, incluindo 17 situações de perseguição, para além dos familiares de mortos e desaparecidos; são situações que não envolvem apenas violações à dignidade humana do indivíduo, mas também pelos projetos de vida interrompidos ou modificados em razão dos efeitos da repressão política. Em seu início, a comissão serviu basicamente como um balcão burocrático sem qualquer ação de reparação simbólica, moral ou quaisquer outras iniciativas do tipo, e por ter um caráter personalíssimo, não compreendeu os processos coletivos (Abrão, 2014). Assim, atendendo a dezenas de milhares de pessoas, a comissão promoveu um imenso sistema reparatório (Abrão \& Torelly, 2011), o que contribuiu para a individualização da temática do acerto de contas no Brasil, ou seja, 
o debate e os efeitos da ditadura permaneceram na esfera privada, sem ampliação à sociedade coletivamente. Sendo assim uma das expressões da política pública de silenciamento.

\section{FASE ANAMNÉSICA DAS DISPUTAS DE NARRATIVAS E O AVANÇO TÍMIDO DAS POLÍTICAS DE MEMÓRIA}

Algumas mudanças fundamentais ocorreram a partir de 2007, sobretudo na adoção de um discurso de justiça de transição por parte dos membros do governo do presidente Luiz Inácio Lula da Silva (2003-2010), adeptos da terceira perspectiva aqui apresentada. Nascido como oposição à ditadura, o Partido dos Trabalhadores introduziu novas dinâmicas de negociação entre o Estado e os movimentos sociais em diversas áreas, inclusive no que concerne às pautas de memória, verdade e justiça, nas quais havia maior proximidade de maneira que ativistas ocuparam postos na estrutura estatal e dela utilizaram para a promoção de suas bandeiras (Abers et al., 2014). Dessa forma, ex-perseguidos políticos assumiram cargos-chave na administração pública e alteraram as práticas de esquecimento hegemônicas até então, iniciando a fase anamnésica das disputas de narrativa (Gómez, 2018). Assim, entre 2007 e 2014, o país observou o avanço de pautas de memória e verdade através do esforço desses atores políticos inclinados à negociação, somado à pressão dos atingidos que tiveram nesse momento um alargamento do espaço de diálogo com o Estado.

Nessa articulação entre as perspectivas dos atingidos, que colocavam suas demandas e dos negociadores, que as tratavam, dois movimentos no âmbito institucional têm maior relevância: o engajamento da Secretaria Especial de Direitos Humanos (SEDH), na figura de Paulo Vannuchi, e a virada hermenêutica da Comissão de Anistia, sob a batuta de Paulo Abrão. O marco inaugural dessa mudança é a publicação do livro Direito à Verdade e à Memória (Brasil, 2007), em 2007, pela SEDH, uma vez que foi o primeiro documento oficial em que o Estado assume a prática sistemática de tortura, mortes e desaparecimento forçado (Torelly \& Abrão, 2010). Já a Comissão de Anistia ocupou o papel de formulador e executor de políticas de memória e verdade de forma a ressignificar a reparação para os atingidos, transformando ainda o próprio conceito de anistia política ao vinculá-la à rememoração, ao invés de impunidade (Alves, 2019).

Com a chamada "virada hermenêutica", a Comissão de Anistia apropriou-se do significado histórico da anistia defendido pelos CBAs durante a campanha na década de 1970 (Alves, 2019), permitindo o estreitamento das relações 
entre os atores partidários da segunda e da terceira perspectivas. Foi criada então uma agenda pública voltada para a dimensão moral da reparação a fim de promover o direito à memória e à verdade que ao longo de sete anos conseguiu avanços relevantes dentro das possibilidades dispostas no cenário político. Dentre as medidas e políticas de memória, podemos citar os projetos Marcas da Memória, o Memórias Reveladas, as Caravanas da Anistia e o Clínicas do Testemunho, que compuseram um importante momento memorial do qual o Brasil não havia experienciado até então. Segundo Gómez, a fase anamnésica só foi possível pelas condições favoráveis no plano político interno e a conjuntura latino-americana propícia à divulgação dos mecanismos de justiça de transição e legitimação do paradigma internacional dos direitos humanos (Gómez, 2018).

Nesse contexto, emergiu a urgência de elaborar um novo programa de direitos humanos, tendo sido o anterior elaborado em 2002, e relatado por Paulo Sérgio Pinheiro durante o segundo mandato de Fernando Henrique (Vannuchi, 2015). A construção dos programas envolvia a convocação de conferências locais, regionais e nacional junto à sociedade civil para levantar as temáticas que comporiam o documento final. No governo petista, foram realizadas 137 conferências, abrangendo cerca de 14 mil pessoas para a formulação do terceiro Programa Nacional de Direitos Humanos (PNDH-3). De modo geral, o PNDH-3 apresentou continuidades em relação às versões anteriores, no entanto, uma grande inovação foi a institucionalização da temática de direito à memória e à verdade, na qual foi proposta a criação da Comissão Nacional da Verdade (CNV). De certo, a preparação do programa não esteve isenta de disputas de narrativas; os adeptos das perspectivas dos conservadores e dos atingidos se enfrentaram intensamente na discussão do sexto eixo em que os primeiros defendiam que o direito à memória não se sobrepunha à Lei de Anistia, portanto, a comissão da verdade não poderia ter poderes para a responsabilização dos agentes, os documentos da repressão deveriam permanecer em sigilo e deveriam evitar revanchismos. Sob a perspectiva dos atingidos, por sua vez, defendiam o direito à memória e à verdade como um direito humano, assim pautavam a revisão da Lei de Anistia e a criação de uma comissão da verdade e justiça que pudesse responsabilizar os perpetradores (Soares, 2016).

Os programas de direitos humanos foram publicados via decreto presencial, porém, a fim de legitimar o PNDH-3, o então ministro da SEDH, Paulo Vannuchi, levou o projeto a todos os ministérios para que fosse por eles ratificados e, assim, obter robustez política (Vannuchi, 2015). Contudo, essa estratégia atrasou a publicação do programa em um ano, principalmente devido ao conflito 
entre a Secretaria de Direitos Humanos e o Ministério da Defesa, ou melhor, entre Vannuchi e Nelson Jobim - a essa altura, Jobim já havia passado pelo Ministério da Justiça no governo Fernando Henrique, se aposentado como ministro do Supremo Tribunal Federal e agora ocupava o posto de ministro da Defesa do governo Lula. Ao longo de um ano, os dois protagonizaram um embate que tomou as páginas dos jornais, cada qual defendendo uma posição a respeito do papel que a comissão da verdade ocuparia no enfrentamento da herança autoritária: para Jobim, "não se constrói o futuro retalhando o passado" (Jobim, 2014), ou seja, a Lei de Anistia deveria se fazer presente da forma como fora concebida: anistia como esquecimento; por sua vez, Vannuchi, defende a necessidade de esclarecimento dos crimes cometidos por agentes públicos durante a ditadura e a punição destes via justiça restaurativa, mas, como partidário da terceira perspectiva, estava disposto a negociar e ajustar alguns pontos possíveis - outros, contudo, eram inegociáveis (Vannuchi, 2019).

Por falhas na comunicação entre eles, a primeira versão do decreto do PNDH-3 foi publicada em dezembro de 2009, sem total acordo de Jobim que, em desagravo, não compareceu à cerimônia de lançamento. Não apenas isso, o ministro ameaçou pedir demissão junto aos comandantes das Forças Armadas, gerando uma crise interna no governo que demandou a intervenção do presidente Lula para mediar o conflito. O principal ponto de desacordo teria sido a exigência de "investigação plena", isto é, dos crimes cometidos pelos "dois lados", garantia que Jobim teria dado aos militares e não fora incluído no decreto (Jobim, 2014). Esse posicionamento, como aponta Gallo, influenciou a opinião pública na imprensa de maneira a classificar todo o eixo de memória e verdade do PNDH-3 como um ato revanchista (Gallo, 2015). Por fim, para encerrar o confronto, em maio de 2010, um novo decreto foi publicado com alterações no programa de direitos humanos a respeito do enfrentamento do passado ditatorial; nota-se, portanto, a política pública de silenciamento mais uma vez bem-sucedida por meio do poder de veto dos militares.

Tendo passado mais de um ano entre a publicação da versão final do PNDH-3 e a promulgação da lei n ${ }^{\circ} 12.528 / 2011$, de criação da CNV, o país acompanhou nesse ínterim o surgimento do "comissionismo", o fenômeno de multiplicação de comissões da verdade locais, municipais, de entidades civis e institucionais (de Hollanda \& Israel, 2019). Essas comissões se originaram a partir da instalação de comitês de acompanhamento do eixo memória e verdade como um meio da sociedade civil de manter a pressão ao governo federal pela instauração efetiva da CNV (Viana, 2014); contavam, então, com a predominância da segun- 
da perspectiva, a dos atingidos políticos. Assim, em setembro de 2011, o projeto de lei foi votado no Congresso Nacional sob muitas críticas dos movimentos sociais - seja pela falta de diálogo com a sociedade para construção do projeto, quanto pelo resultado aquém do esperado (M. A. de A. Teles, 2015; Vital Brasil, 2019). Por outro lado, muitos atores da terceira perspectiva operaram intensas negociações entre os parlamentares a fim de que fosse aprovado mesmo com as resistências dos militares.

Costurada a articulação política por uma comissão da verdade sem caráter punitivo, o debate entre os parlamentares centrou-se mais em discussão de emendas ao projeto original e menos se seria ou não criada a comissão. Os deputados e senadores de partidos à esquerda e centro-esquerda focaram em apontar que a comissão representava um avanço dos direitos humanos no Brasil e não havia interesse revanchista (Barros, 2020); os de centro e direita também foram favoráveis à $\mathrm{CNV}$, embora foram mais silenciosos, à exceção do deputado Jair Bolsonaro que, responsável por quase metade das manifestações desse bloco, demonstrava oposição explícita, ainda que pouco expressiva naquele momento (Barros, 2020; Bauer, 2015; Sainz et al., 2020). Finalmente a CNV é criada via lei ${ }^{\circ} 12.528$, de 18 de novembro de 2011, com o propósito de promover a reconciliação nacional, observadas as disposições da Lei de Anistia.

O início dos trabalhos da CNV foi marcado por controvérsias, conflitos internos e desgaste público em vista do embate entre as perspectivas de tratamento do passado autoritário - até mesmo entre os membros. A primeira polêmica deu-se após a declaração do comissionário José Carlos Dias, ex-ministro da Justiça do governo Fernando Henrique, de que a comissão deveria investigar as ações dos militantes de esquerda além das violações cometidas pelos agentes da repressão (Credendio, 2012). Sua fala gerou reações entre os movimentos sociais (Viana, 2014), outros atores políticos e entre os demais membros da comissão que logo publicaram a resolução $\mathrm{n}^{0} 2$, dispondo que a comissão investigaria as violações de direitos humanos cometidos por "agentes públicos, pessoas a seu serviço, com apoio ou no interesse do Estado". Jobim, que a essa altura já não ocupava cargo público, interpretou essa resolução como uma modificação do escopo da lei $\mathrm{n}^{\circ} 12.528$, isto é, um retorno a algo que havia sido derrotado dentro do governo durante a elaboração do PNDH-3 (Jobim, 2014).

As três perspectivas de tratamento do passado autoritário que apresentamos aqui, aparecem nitidamente entre os sete membros da CNV, o que Torelly chamou de "a conflict between competing expectations" (Torelly, 2018, p. 9), no debate a respeito da maneira como a comissão lidaria com as investigações. Pela 
primeira perspectiva, seria produzido um relatório final apenas sistematizando as informações já existentes observando as limitações impostas pela Lei de Anistia, operando de maneira discreta e, assim, encerrar um capítulo da história; contrariamente, pela segunda perspectiva, a sociedade seria mobilizada para exigência de responsabilização e de aprofundamento da agenda de direitos humanos no país, para tal, a comissão deveria publicizar os resultados das investigações, bem como expor os nomes dos perpetradores e organizar políticas públicas. Em direções completamente contrárias, essas perspectivas divergentes se enfrentaram no decorrer do primeiro ano de funcionamento da comissão, até que a terceira perspectiva assume seu lugar no debate na figura de Paulo Sérgio Pinheiro: a comissão não publicaria seus achados durante a pesquisa, em contrapartida o relatório final questionaria a impunidade aos agentes públicos e recomendaria a revisão da Lei de Anistia (Torelly, 2018). Embora não tenha agradado a todos, essa decisão alcançou a maioria entre os membros, inclusive porque apesar de manter o trabalho longe do público, individualmente os comissionários estiveram livres para engajarem-se nos movimentos e organismos de direitos humanos (Torelly, 2018).

Não obstante essa abordagem possa ser bastante criticada, Torelly relembra que a estratégia evitou vazamentos para a imprensa acerca das divisões internas, logo prevenindo que o trabalho da $\mathrm{CNV}$ fosse deslegitimado pelos seus oponentes (Torelly, 2018). Posto isto, é importante ressaltar que a entrega do relatório final ocorreu em dezembro de 2014, quando se iniciava a crise política e econômica que ainda assola o país. Inclusive, a própria cerimônia de entrega do relatório demarca esse momento - o fim da fase anamnésica -, por exemplo, ao contrário da inauguração, o encerramento contou apenas com alguns poucos convidados e sem a presença dos demais ex-presidentes democráticos. Ainda que seu lançamento tenha sido abafado pela crise que culminou no impeachment da presidenta Dilma Rousseff pouco mais de um ano depois, alguns resultados positivos podem ser destacados. A comissão concluiu que as violações contra os direitos humanos não só ocorreram, como era uma prática sistemática e amplamente adotada sob conhecimento dos superiores - inclusive dos generais-presidentes -, portanto rejeitando a narrativa de que as práticas repressivas seriam apenas excessos individuais de poucos agentes públicos (Brasil. Comissão Nacional da Verdade, 2014). 


\section{O INÍCIO DO FIM: O BRASIL DEPOIS DO RELATÓRIO FINAL DA CNV}

A fase anamnésica foi encerrada abruptamente com a crise política que retirou o Partido dos Trabalhadores do poder, deixando o vice-presidente Michel Temer no comando do governo federal. A partir desse momento, é observado o início do desmonte das políticas de memória e verdade com o esvaziamento da Comissão de Anistia, modificando o seu caráter de formulador e executor dessas políticas e interrompendo a continuidade dos seus projetos. Ainda, no aspecto simbólico, foi suspenso o pedido de desculpas ao atingido em nome do Estado no momento da concessão da declaração de anistiado político (Éboli, 2018). Já em um processo de apagamento, não mais silenciamento, a Comissão tornou-se o vetor de uma estratégia de contranarrativa de exaltação do período autoritário (Cateb et al., 2020). Esse apagamento das políticas de memória e verdade está relacionado com a emergência da quarta perspectiva que margeava os embates que mencionamos aqui, porém de maneira pouco expressiva e sequer encontrando lugar de destaque no debate público por décadas. Trata-se da perspectiva dos apologistas, isto é, a defesa explícita e saudosista da ditadura, com forte apoio às Forças Armadas, mantendo a narrativa construída pelos militares de que havia uma guerra, que o golpe de 1964 foi uma revolução (ou "contrarrevolução") para conter ou evitar o comunismo e tratam os atingidos como terroristas, independentemente do papel ocupado nos movimentos de resistência. Desde 2015, contudo, essa perspectiva encontrou voz em redes sociais entre grupos antipetistas, sobretudo sob o discurso inflado (e inflamatório) do deputado Jair Bolsonaro. Em 2018, ele foi eleito presidente da República do Brasil.

\section{REFERÊNCIAS BIBLIOGRÁFICAS}

Abers, R., Serafim, L., \& Tatagiba, L. (2014). Repertórios de interação estado-sociedade em um estado heterogêneo: A experiência na Era Lula. Revista Dados, 57(2), 325-357. http://dx.doi.org/10.1590/0011-5258201411

Abrão, P. (2014). Paulo Abrão Pires Junior (depoimento). CPDOC/Fundação Getulio Vargas (FGV).

Abrão, P., \& Torelly, M. (2011). O programa de reparações como eixo estruturante da justiça de transição no Brasil. In F. Reátegui (Org.), Justiça de transição: Manual para a América Latina (p. 473-516). Comissão de Anistia, Ministério da Justiça; Centro Internacional para a Justiça de Transição. 
Alves, G. G. (2019). Os sentidos da anistia brasileira e a Virada Hermenêutica da Comissão de Anistia. In C. A. Gallo (Org.), Anistia: Quarenta anos, uma luta, múltiplos significados (p. 283-312). Gramma.

Barros, A. T. de. (2020). O debate parlamentar sobre a Comissão Nacional da Verdade no Congresso Nacional Brasileiro. Revista Brasileira de Ciências Sociais, 35(104). https://doi.org/10.1590/3510401/2020

Bauer, C. S. (2011). Um estudo comparativo das práticas de desaparecimento nas ditaduras civilmilitares argentina e brasileira e a elaboração de políticas de memória em ambos os países [Tese de doutorado, Universidade Federal do Rio Grande do Sul/Universitat de Barcelona] Lume - Repositório Digital da UFRGS. https://www.lume.ufrgs.br/handle/10183/29576

Bauer, C. S. (2015). O debate legislativo sobre a criação da Comissão Nacional da Verdade e as múltiplas articulações e dimensões de temporalidade da ditadura civil-militar brasileira. Anos 90, 22(42), 115-152. https://doi.org/10.22456/1983-201X.53185

Brasil. (2007). Direito à memória e à verdade (1a ed). Secretaria Especial dos Direitos Humanos da Presidência da República.

Brasil. Comissão Nacional da Verdade. (2014). Relatório Comissão Nacional da Verdade. Vol. 1: Vol. v. 1. CNV. http://cnv.memoriasreveladas.gov.br/images/pdf/relatorio/volume_1_digital.pdf

Cateb, C., Osmo, C., Franco, P., \& Benetti, P. (2020). A Comissão Especial sobre Mortos e Desaparecidos Políticos e a Comissão de Anistia no primeiro ano do governo Bolsonaro. In E. Teles \& R. H. Quinalha (Orgs.), Espectros da ditadura: Da Comissão da Verdade ao bolsonarismo (pp. 271-308). Autonomia Literária.

Credendio, J. E. (2012, maio 14). Comissão da Verdade deve analisar os dois lados, diz integrante. Folha de São Paulo. https://m.folha.uol.com.br/poder/2012/05/1089951-comissao-da-verdade-deve-analisar-os-dois-lados-diz-integrante.shtml

D’Araújo, M. C. (2012). O estável poder de veto Forças Armadas sobre o tema da anistia política no Brasil. Varia Historia, 28(48), 573-597. https://doi.org/10.1590/S010487752012000200006

de Hollanda, C. B., \& Israel, V. P. (2019). Panorama das Comissões da Verdade no Brasil: Uma reflexão sobre novos sentidos de legitimidade e representação democrática. Revista de Sociologia e Politica, 27(70), 21. https://doi.org/10.1590/1678-987319277006

Éboli, E. (2018, junho 11). Governo Temer suspende pedido de desculpas às vítimas da ditadura. Gazeta do Povo. https://www.gazetadopovo.com.br/politica/republica/governo-temer-suspende-pedido-de-desculpas-as-vitimas-da-ditadura-13klbj0uqdjr0ni19mc8dbi0w/

Fico, C. (2012). Brasil: A transição inconclusa. In C. Fico, M. P. N. Araujo, \& M. Grin (Orgs.), Violência na história: Memória, trauma e reparação (p. 25-37). Ponteio.

Gallo, C. A. (2015). A Comissão Nacional da Verdade e a reconstituição do passado recente brasileiro: Uma análise preliminar da sua atuação. Estudos de Sociologia, 20(39), 327-345.

Gómez, J. M. (Org.). (2018). Lugares de memória: Ditadura militar e resistências no Estado do Rio de Janeiro. Editora PUC-Rio. 
Gregori, J. (2015). José Gregori II (depoimento). CPDOC/Fundação Getulio Vargas (FGV).

Jobim, N. (2014, novembro 29). O direito à verdade em alguns aspectos políticos: $O$ direito à verdade e anistia-Parte 3 [Video]. YouTube. https://youtu.be/D6vL8EmO0ug

Mezarobba, G. (2008). O preço do esquecimento: As reparações pagas às vítimas do regime militar (uma comparação entre Brasil, Argentina e Chile) [Tese de doutorado, Universidade de São Paulo]. Repositório da Produção USP. https://repositorio.usp.br/item/001695602

Motta, R. P. S. (2018). Cultura política e ditadura: Um debate teórico e historiográfico. Revista Tempo e Argumento, 10(23), 109-137. https://doi.org/10.5965/2175180310232018109

Padrós, E. S. (2004). Memória e esquecimento das ditaduras de segurança nacional: Os desaparecidos políticos. História em revista. Pelotas, RS., (10), 153-168.

Quinalha, R. H. (2013). Com quantos lados se faz uma verdade? Notas sobre a Comissão Nacional da Verdade e a "teoria dos dois demônios". Revista Jurídica da Presidência, 15(105), 181204. https://doi.org/10.20499/2236-3645.RJP2013v15e105-71

Rodeghero, C. S. (2012). Anistia, esquecimento, conciliação e reconciliação: Tensões no tratamento da herança da ditadura no Brasil. In A. Montenegro, C. S. Rodeghero, \& M. P. N. Araujo (Orgs.), Marcas da memória: História oral da anistia no Brasil (pp. 97-135). Ed. Universitária da UFPE.

Sainz, N. G., Silveira, R. A., \& Gallo, C. A. (2020). Entre a apuração e o negacionismo: A percepção $\operatorname{dos}\left(\right.$ as) deputados(as) federais da $53^{\circ}$ e $54^{\circ}$ legislaturas sobre a implementação da lei da Comissão Nacional da Verdade no Brasil. Revista Eletrônica Direito e Política, Programa de Pós-Graduação Stricto Sensu em Ciência Jurídica da UNIVALI, 15(1), 315-346.

Soares, A. (2016). Atores e ideias na constituição do direito à memória e à verdade: Análise da mudança política no Programa Nacional de Direitos Humanos [Tese de doutorado, Universidade Federal de São Carlos]. Repositório Institucional da UFSCar. https://repositorio.ufscar.br/handle/ufscar/8156

Teles, E. (2015). Democracia e estado de exceção: Transição e memória política no Brasil e na Africa do Sul. Editora Fap-Unifesp.

Teles, M. A. de A. (2015). Maria Amélia de Almeida Teles (depoimento). CPDOC/Fundação Getulio Vargas (FGV).

Torelly, M. (2018). Assessing a Late Truth Commission: Challenges and Achievements of the Brazilian National Truth Commission. International Journal of Transitional Justice, 12(2), 122. https://doi.org/10.1093/ijtj/ijy002

Torelly, M., \& Abrão, P. (2010). Justiça de transição no Brasil: A dimensão da reparação. In B. S. Santos, P. Abrão, C. M. dos Santos, \& M. Torelly (Orgs.), Repressão e Memória Política no Contexto Ibero-Brasileiro: Estudos sobre Brasil, Guatemala, Moçambique, Peru e Portugal. Comissão de Anistia, Ministério da Justiça; Centro de Estudos Sociais, Universidade de Coimbra.

Vannuchi, P. de T. (2015). Paulo de Tarso Vannuchi (depoimento). CPDOC/Fundação Getulio Vargas (FGV). 
Vannuchi, P. de T. (2019). Paulo Vannuchi (depoimento). [Entrevista concedida a] Luciana Lombardo, Lucas Pedretti, Dulce Pandolfi e José Sérgio Leite Lopes. Rio de Janeiro, 11 de julho de 2019. (Disponível no acervo da Comissão da Memória e Verdade da UFRJ).

Viana, G. A. (2014). Gilney Amorim Viana (depoimento). CPDOC/Fundação Getulio Vargas (FGV).

Vital Brasil, V. L. C. (2019). Vera Vital Brasil (depoimento). [Entrevista concedida a] Luciana Lombardo, Virna Plastino, Felipe Magaldi e José Sérgio Leite Lopes. Rio de Janeiro, 31 de maio de 2019. (Disponível no acervo da Comissão da Memória e Verdade da UFRJ). 